\title{
SUPPLEMENTAL INFORMATION: Effects of Model Shape, Volume and Softness of the Capsid for DNA Packaging of phi29
}

\author{
Cecilia Bores, Michael Woodson, Marc C. Morais, and B. Montgomery Pettitt** \\ University of Texas Medical Branch \\ E-mail: mpettitt@UTMB.EDU
}

\section{Models and statistically independent simulations}

We have summarized the details of the capsid models and parameters of all the simulations performed within this contribution. The number of statistically independent runs performed for each case has also been indicated:

Table S1: Details and number of all the simulations performed along the manuscript.

$\begin{array}{llllll}\text { Walls } & \text { Parameters } & \text { Shape } & \text { Size } & \text { DNA Twist } & \text { Number of runs } \\ \text { Rigid } & \text { Average } & \text { Spherical } & \text { Unoptimized } & \text { No } & 1 \\ \text { Rigid } & \text { Sequence Dependent } & \text { Spherical } & \text { Unoptimized } & \text { No } & 1 \\ \text { Rigid } & \text { Average } & \text { Spherical } & \text { Unoptimized } & \text { Yes } & 13 \\ \text { Rigid } & \text { Sequence Dependent } & \text { Spherical } & \text { Unoptimized } & \text { Yes } & 7 \\ \text { Rigid } & \text { Average } & \text { Spherical } & \text { Fitting experimental value } & \text { Yes } & 5 \\ \text { Rigid } & \text { Sequence Dependent } & \text { Spherical } & \text { Fitting experimental value } & 6 \\ \text { Soft } & \text { Average } & \text { Elongated } & \text { Fitting experimental value } & \text { Yes } & 5 \\ \text { Soft } & \text { Sequence Dependent } & \text { Elongated } & \text { Fitting experimental value } & \text { Yes } & 1 \\ \text { Rigid } & \text { Average } & \text { Elongated } & \text { Fitting experimental value } & \text { Yes } & \end{array}$

\section{Capsid volume estimation}

Starting from an atomic reconstruction of the capsid of phage phi29 we have calculated the inner cavity by means of the following Monte Carlo integration procedure: We divided the 
volume of the cubic box containing the capsid with a grid and classified the cells according to whether they are in the internal region of the capsid or not. We performed a MC procedure of several millions steps with a probe particle of radius $=1 \mathrm{~nm}$ to calculate the inner volume available to the center of mass of the DNA helix. The insertion trials were refused if they were in a cell labelled as external. Thus, the capsid internal volume accessible to the center of mass of the base-pairs is given by: $V_{\text {capsid }}=\frac{\text { Number of accepted insertions }}{\text { Number of trials }} \times V_{\text {box }}$

Table S2: Details about the capsid inner volume calculation by means of MC integration.

$\begin{array}{lccccc}\text { Phage } & \text { PDB file } & V_{\text {box }}\left(\mathrm{nm}^{3}\right) & \text { Number of trials } & \text { Number of insertions } & V_{\text {capsid }}\left(\mathrm{nm}^{3}\right) \\ \text { T5st(0) } & \text { PDB: 6OMC } & 83 \times 83 \times 83 & 5 \text { millions } & 1967528 & 225032.26 \\ \text { T7 } & \text { PDB: 3J7X } & 67 \times 67 \times 67 & 5 \text { millions } & 1250002 & 75190.87 \\ \text { phi29 empty } & \text { Current study } & 47 \times 47 \times 66 & 50 \text { millions } & 9401407 & 27413.37 \\ \text { phi29 full } & \text { Current study } & 47 \times 47 \times 66 & 10 \text { millions } & 2163641 & 31544.59\end{array}$

\section{DNA orientation}

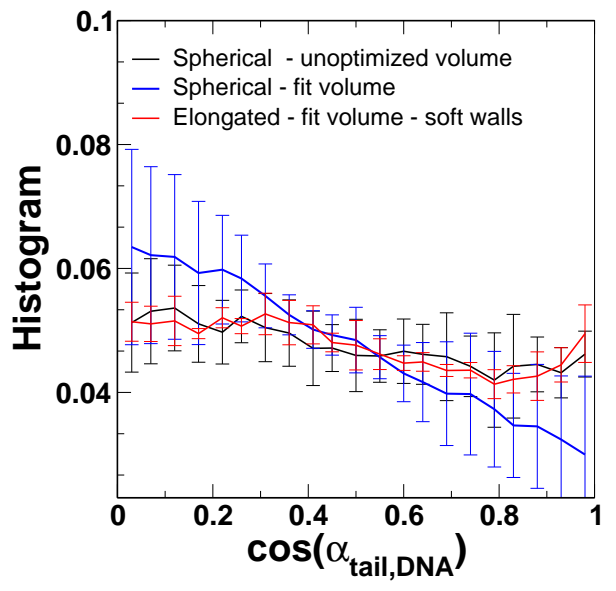

Figure S1: Orientational distribution profiles for DNA using the sequence dependent parameterization. This shows the histogram of the cosine of angle $\alpha_{t a i l, D N A}$ for the spherical (blue line) and elongated model (red line) fitting the volume measured from experimental cryoEM data and for the spherical model with an unoptimized volume (black line). 


\section{DNA twisting effect}

Snapshots of the final conformations, radial density profiles and correlation functions for the spherical case with and without including DNA twisting while packing the DNA inside the capsid. For more information about these features see our previous contribution. ${ }^{1}$

\section{a) NO twist}

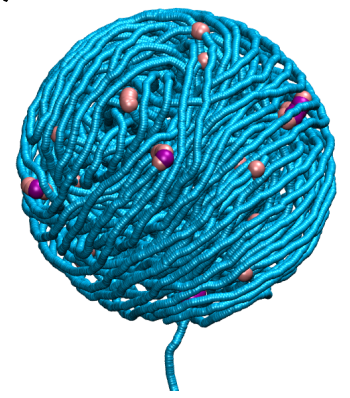

b) Twist

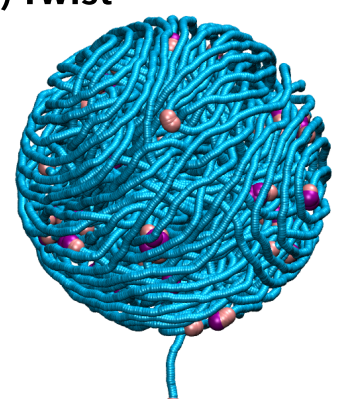

Figure S2: Snapshots of the final conformation of DNA confined inside the capsid for the No twist (a) and Twist (b) situations emphasizing the presence of defects: light pink represents roll angles larger than $1.1 \mathrm{rad}$ and fucsia represents bubbles. Only the center of mass of each base pair has been represented for clarity.
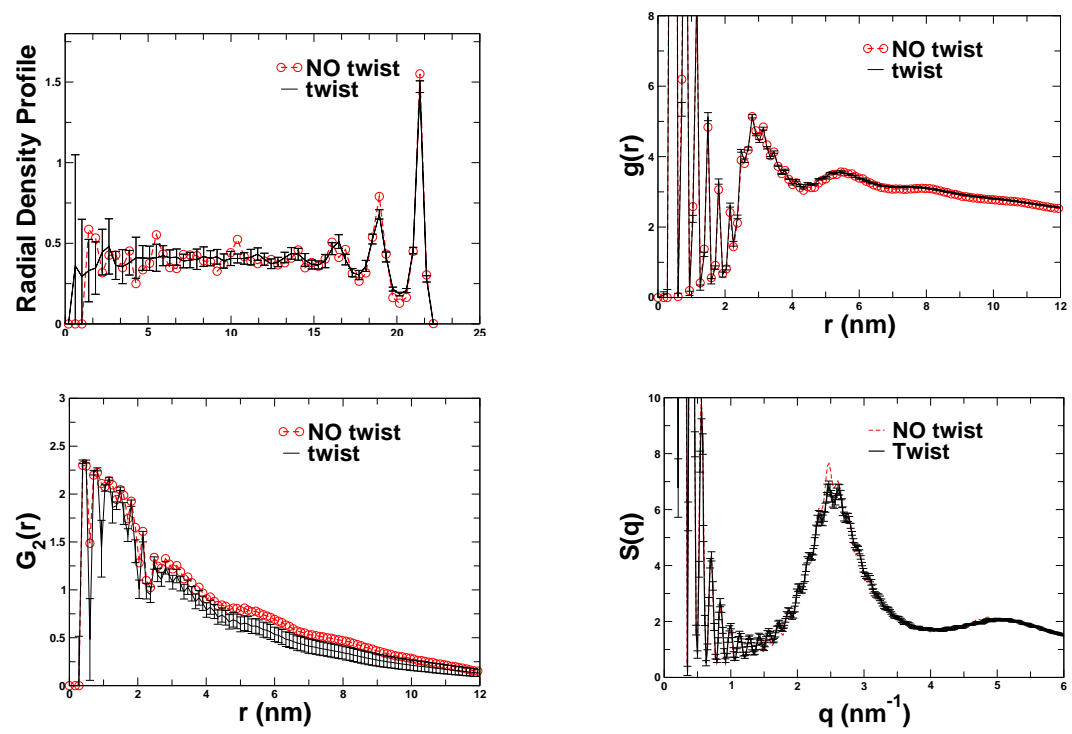

Figure S3: From top left to right bottom: Radial density profiles, radial correlation functions, angular correlation functions and structure factors for the spherical case with and without including DNA twisting while inserting the DNA inside the capsid. 


\section{Distribution of roll angles}

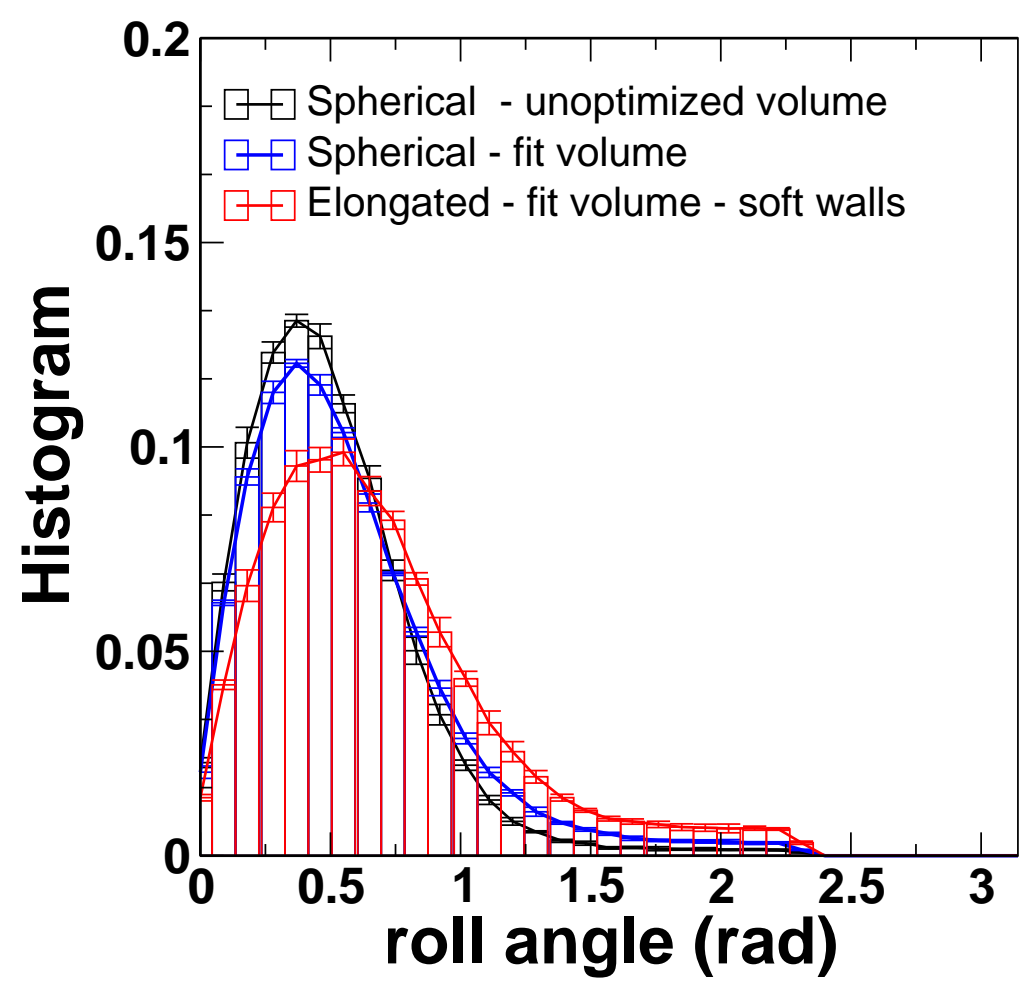

Figure S4: Distribution of roll angles along the confined dsDNA macromolecule for the three capsid models here considered: for the spherical (blue line) and elongated model (red line) fitting the volume measured from experimental cryoEM data and for the spherical model with an unoptimized volume (black line)

\section{References}

(1) Bores, C.; Pettitt, B. M. Structure and the role of filling rate on model dsDNA packed in a phage capsid. Phys. Rev. E 2020, 101, 012406. 